\title{
Incidência de podridões do colmo, grãos ardidos e produtividade de grãos de genótipos de milho em diferentes sistemas de manejo ${ }^{1}$
}

\author{
Incidence of stalk rot, rot grains and grain yield of maize genotypes \\ in different management systems
}

\author{
Noel Alves Ribeiro ${ }^{2}$ Ricardo Trezzi Casa ${ }^{2}$ Amauri Bogo ${ }^{3}$ \\ Luis Sangoi ${ }^{3}$ Eder Novaes Moreira $^{4}$ Leonardo Almeida Wille ${ }^{4}$
}

\section{RESUMO}

A monocultura do milho é uma prática comum em algumas regiões do Brasil, sendo responsável pelo incremento dos danos causados pelas doenças. O objetivo deste trabalho foi avaliar o efeito de diferentes sistemas de produção de milho contrastantes quanto ao investimento em manejo sobre a incidência de podridões do colmo, grãos ardidos e produtividade de grãos. Foram testados quatro sistemas: S1 (baixo nível de manejo), S2 (médio), S3 (alto) e S4 (proposto para maximizar o produtividade). Os níveis de manejo diferiram quanto à densidade de semeadura, espaçamento entre linhas, quantidade de fertilizantes e uso da irrigação. Em cada sistema, foram utilizadas três genótipos de milho: BRS Planalto (variedade de polinização aberta), Traktor (híbrido duplo) e P32R21 (híbrido simples). Os experimentos foram conduzidos nas safras 2002/03 e 2003/04, em área de plantio direto e monocultura, sob sucessão de cobertura morta de aveia preta+ervilhaca. $O$ delineamento experimental foi em blocos casualizados, com parcelas subdivididas e quatro repetições. Nas duas safras agrícolas, a variedade Planalto apresentou maior incidência de podridões do colmo do que os híbridos em todos os sistemas de manejo. O fungo Colletotrichum graminicola foi o principal patógeno associado às podridões do colmo. A produtividade de grãos oscilou entre 3.986 a $13.489 \mathrm{~kg} \mathrm{ha}^{-1}$ em 2003 e entre 1.787 a $13.849 \mathrm{~kg} \mathrm{ha}^{-1}$ em 2004, variando conforme o genótipo e o sistema de produção. As maiores produtividades foram obtidas em S4 com a utilização do híbrido simples P32R21. A incidência de grãos ardidos nas duas safras foi baixa, não atingindo em nenhum tratamento o valor de 6\% considerado no desconto. O fungo Fusarium verticillioides foi o principal patógeno associado aos grãos ardidos. Por outro lado, C. graminicola não foi detectado nos grãos ardidos, demonstrando que sua alta incidência nos colmos não significa sua presença nos grãos. Não foi possível identificar um sistema de manejo que reduzisse a incidência de podridões do colmo e grãos ardidos na cultura do milho.

Palavras-chave: Zea mays, doenças, monocultura, plantio direto.

\section{ABSTRACT}

Maize monoculture is an usual practice in some regions of Brazil, being responsible for the growing damage caused by diseases. The objective of this work was to evaluate the effect of different maize production systems, contrasting in management investments, on the incidence of stalk rot, rot grains and grain yield. Four production systems were tested: S1 (low management level), $S 2$ (medium), S3 (high) e S4 (designed to maximize the grain yield). The production systems differed in relation to plant density, row spacing, amount of fertilizer and irrigation use. Three genotypes were used for each production system: BRS Planalto (open-pollinated variety), Traktor (double-cross hybrid) and P32R21 (single-cross hybrid). The experiments were carried out during 2002/03 and 2003/04 grown seasons, in no-till system and a monoculture area, having a mixture of black oat and vetch as the preceding winter crop. The experiments was a split-plot arranged in randomized complete blocks design with four replications. In both grown seasons, regardless management system, open-pollinated variety BRS Planalto showed higher stalk rot than the hybrids. Colletotrichum graminicola was the main pathogen associated with stalk rot. Grain yield ranged from 3,986 to $13.489 \mathrm{~kg} \mathrm{ha}^{-1}$ in 2003 and from 1,787 to $13.849 \mathrm{~kg} \mathrm{ha}^{-1}$ in 2004 , depending on genotype and crop management system. The highest values of grain yield were obtained in S4 with the single-cross hybrid. The incidence of rot grain was low (below 6\%) during the whole experimental period. Fusarium verticillioides was the main pathogen associated with rot grain. There was no association between incidence and causal agent of stalk rot and rot grain. It was not possible to identify a crop

${ }^{1}$ Parte da dissertação apresentada pelo primeiro autor à Universidade do Estado de Santa Catarina (UDESC) para obtenção do título de Mestre em Produção Vegetal. Moreira e Wille, bolsistas do Conselho Nacional de Desenvolvimento Científico e Tecnológico (CNPq).

${ }^{2}$ Curso de Produção Vegetal, UDESC, Lages, SC, Brasil.

${ }^{3}$ UDESC, Lages, SC, Brasil. E-mail: a2rtc@ cav.udesc.br

${ }^{4}$ Curso de Agronomia, UDESC, Lages, SC, Brasil. 
management system that was more efficient to reduce incidence of stalk rot and rot grain.

Key words: Zea mays, diseases, monoculture, no till.

\section{INTRODUÇÃO}

Na Região Sul do Brasil, as principais doenças do milho (Zea mays L.) estão relacionadas com a germinação de sementes, podridões do colmo e da espiga e algumas doenças foliares (REIS \& CASA, 2001). Os fungos Colletotrichum graminicola (Ces.) G.W.Wils, Stenocarpella maydis (Berk.) Sutton, S. macrospora (Earle) Sutton, Fusarium graminearum (Schwabe) e Fusarium verticillioides J. Sheld. são os patógenos mais encontrados associados às podridões do colmo (PEREIRA, 1997; REIS et al., 2004). Com exceção de $\boldsymbol{C}$. graminicola, os demais fungos são detectados causando podridões de espiga, sendo freqüentemente isolados de grãos ou sementes de milho (CASA et al., 1998; PINTO, 1998). A maior intensidade de podridões de espiga normalmente ocasiona maior incidência de grãos ardidos, indesejáveis na comercialização, pois é descontado do preço de venda um percentual referente à incidência de grãos ardidos.

Os fungos causadores de podridões do colmo e da espiga sobrevivem principalmente nos restos culturais e na semente de milho infectada (CASA et al., 1998; PINTO, 1998; REIS \& CASA, 2000). O cultivo do milho em monocultura e plantio direto favorece a sobrevivência, a manutenção e a multiplicação do inóculo destes fungos (ZAMBOLIM et al., 2000).

Alguns trabalhos de pesquisa têm demonstrado haver uma redução na intensidade das podridões do colmo e da espiga quando o milho é cultivado em rotação de culturas (DENTI \& REIS, 2001; TRENTO et al., 2002). Por outro lado, as espécies vegetais utilizadas antecedentes ao milho, como forma de cobertura morta em plantio direto, podem anular o efeito da rotação, por serem hospedeiras dos agentes causais dessas doenças em milho. Além disso, o nível tecnológico empregado pelos agricultores é variável entre propriedades. A diferença entre fornecimento de insumos (tipo, quantidade, época de fornecimento), escolha do arranjo espacial, manejo de plantas invasoras e pragas, e a escolha do material genético, também podem afetar a ocorrência e a intensidade das doenças.

A prática de semeadura direta do milho em monocultura representa uma atividade muito adotada entre os pequenos e médios produtores do estado de
Santa Catarina. Diante do exposto, o objetivo do trabalho foi avaliar o efeito de quatro níveis tecnológicos de manejo da cultura, em área de semeadura direta e monocultura, na incidência de podridões do colmo, grãos ardidos e na produtividade de grãos de três genótipos de milho.

\section{MATERIAL E MÉTODOS}

O trabalho foi desenvolvido no município de Lages, região fisiográfica do Planalto Sul do estado de Santa Catarina, localizado a $27^{\circ} 52$ ' $30^{\prime \prime}$ de latitude sul e $50^{\circ} 29^{\prime} 45^{\prime \prime}$ de longitude oeste, a 930 metros acima do nível do mar. Os experimentos foram conduzidos nas safras agrícolas de 2002/03 e 2003/04, instalados em área de semeadura direta com monocultura de três anos e sob sucessão de cobertura morta de aveia+ervilhaca. As parcelas constaram de seis linhas de semeadura com cinco metros de comprimento. $\mathrm{O}$ delineamento experimental foi de parcelas subdividas, com quatro repetições. Na parcela principal, foram alocados os sistemas de produção e nas subparcelas os genótipos de milho.

Foram testados quatro sistemas de produção, equivalentes a diferentes níveis de manejo e expectativas de produtividade de grãos. Os sistemas 1,2 e 3 (S1, S2 e S3) foram fundamentados nas recomendações técnicas para a cultura de milho no estado do Rio Grande do Sul (INDICAÇÕES TÉCNICAS, 2001), representando, respectivamente, baixo, médio e alto nível de manejo. O sistema 4 (S4) foi proposto objetivando potencializar a produtividade de grãos. Em cada sistema de produção, foram utilizados três genótipos: a variedade de polinização aberta (VPA) BRS Planalto, o híbrido duplo (HD) Traktor e o híbrido simples (HS) Pioneer 32R21. Os sistemas de produção diferiram quanto à densidade de semeadura, espaçamento entre plantas e quantidade de $\mathrm{N}, \mathrm{P}_{2} \mathrm{O}_{5}$ e $\mathrm{K}_{2} \mathrm{O}$ utilizado por tratamento, conforme descritos na tabela 1 .

As semeaduras foram realizadas em 20/ $11 / 2002$ e $22 / 10 / 2003$, as quais foram efetuadas manualmente 45 dias após a dessecação da cobertura de inverno. Quando o milho apresentou quatro folhas expandidas, foi feito o desbaste para ajuste das densidades estabelecidas nos sistemas. A adubação fosfatada e potássica foi aplicada nos sulcos de semeadura, no dia da implantação do ensaio. Foram aplicados $30 \mathrm{~kg} \mathrm{ha}^{-1} \mathrm{de} \mathrm{N}$ na base em todos os sistemas. No S3 e S4, a quantidade de água disponível no solo foi mantida próxima à capacidade de campo, com irrigação por aspersão numa intensidade de precipitação de $12 \mathrm{~mm}$ hora $^{-1}$ realizada 
Tabela 1 - Principais características de manejo de quatro sistemas de produção de genótipos de milho com diferentes bases genéticas. Lages, SC.

\begin{tabular}{|c|c|c|c|c|c|c|c|}
\hline \multirow{2}{*}{ Nível de manejo } & \multirow{2}{*}{ Base genética } & \multirow{2}{*}{ Genótipo } & \multirow{2}{*}{ Densidade $\left(\mathrm{pl} \mathrm{ha}^{-1}\right)$} & \multirow{2}{*}{ Espaçamento entre linhas $(\mathrm{cm})$} & \multicolumn{3}{|c|}{ Adubação $\left(\mathrm{kg} \mathrm{ha}^{-1}\right)$} \\
\hline & & & & & $\mathrm{N}$ & $\mathrm{P}_{2} \mathrm{O}_{5}$ & $\mathrm{~K}_{2} \mathrm{O}$ \\
\hline \multirow{3}{*}{ Baixo-S1 } & VPA & BRS Planalto & 30.000 & 80 & 30 & 25 & 30 \\
\hline & HD & Traktor & 30.000 & 80 & 30 & 25 & 30 \\
\hline & HS & $\mathrm{P} 32 \mathrm{R} 21$ & 30.000 & 80 & 30 & 25 & 30 \\
\hline \multirow{3}{*}{ Médio-S2 } & VPA & BRS Planalto & 50.000 & 80 & 60 & 40 & 60 \\
\hline & HD & Traktor & 50.000 & 80 & 60 & 40 & 60 \\
\hline & HS & $\mathrm{P} 32 \mathrm{R} 21$ & 50.000 & 80 & 60 & 40 & 60 \\
\hline \multirow{3}{*}{ Alto-S3 } & VPA & BRS Planalto & 50.000 & 80 & 90 & 70 & 100 \\
\hline & HD & Traktor & 60.000 & 80 & 90 & 70 & 100 \\
\hline & HS & P32R21 & 70.000 & 80 & 90 & 70 & 100 \\
\hline \multirow{3}{*}{ Potencial-S4 } & VPA & BRS Planalto & 60.000 & 40 & 144 & 112 & 160 \\
\hline & HD & Traktor & 70.000 & 40 & 144 & 112 & 160 \\
\hline & HS & P32R21 & 100.000 & 40 & 144 & 112 & 160 \\
\hline
\end{tabular}

VPA = variedade cultivada de polinização aberta; $\mathrm{HD}=$ híbrido duplo; $\mathrm{HS}$ = híbrido simples

quando o potencial de água no solo foi inferior a $0.04 \mathrm{MPa}$.

A incidência das podridões do colmo foi quantificada segundo metodologia proposta por REIS et al. (1998). Considerou-se sintomática a planta que apresentou descoloração do primeiro ou segundo entrenó e/ou aquela com menor resistência à pressão dos dedos polegar e indicador. Os colmos sintomáticos foram cortados e levados ao Laboratório de Fitopatologia do CAV/UDESC, onde de cada colmo foram retirados dois fragmentos do tecido interno da medula (região próxima ao nó). Os fragmentos foram desinfestados em hipoclorito de sódio a $1 \%$ durante três minutos, com posterior transferência para caixas gerbox contendo meio de cultura de $\mathrm{BDA}+\mathrm{A}$ (batatadextrose-ágar $=$ Oxoid: $39 \mathrm{~g} \mathrm{~L}^{-1}$ de água+antibiótico $=$ $200 \mathrm{mg} \mathrm{L}^{-1}$ de sulfato de estreptomicina), visando ao desenvolvimento de fungos. Os dados obtidos foram expressos em incidência de podridões do colmo e de fungos isolados para cada tratamento.

A produtividade de grãos foi determinada coletando-se as espigas das plantas das fileiras centrais de cada parcela. As espigas foram despalhadas e trilhadas, e os grãos foram secos em estufa até a obtenção de massa constante. Os grãos foram pesados e os valores obtidos convertidos para 1,0 hectare na umidade padrão de $13 \%$.

A percentagem de grãos ardidos foi obtida pela separação manual dos grãos sintomáticos (ardidos) dos grãos sadios, em uma amostra de $250 \mathrm{~g}$ de semente de cada parcela (BRASIL, 1996). Os grãos ardidos foram pesados e o seu peso transformado em percentagem. Também realizou-se a incidência de fungos nos grãos ardidos, selecionando-se visualmente 400 grãos sintomáticos, os quais foram desinfestados e plaqueados em meio de BDA+A. O material foi incubado durante sete dias à temperatura de $25^{\circ} \mathrm{C}$ e fotoperíodo de $12 \mathrm{~h}$. Considerou-se infectado o grão sob o qual se desenvolveram colônias e/ou estruturas dos fungos, visualizada em lupa esteroscópica, segundo descrito por CASA et al. (1998) e PINTO (1998). Os dados foram expressos em incidência para cada fungo detectado.

Os dados de incidência de podridões do colmo, grãos ardidos e de produtividade de grãos foram submetidos à análise de variância com as médias comparadas pelo teste de Tukey à $5 \%$ de probabilidade de erro.

\section{RESULTADOS E DISCUSSÃO}

A variedade Planalto apresentou a maior incidência média de podridão do colmo (PC) nos quatro sistemas de manejo e nas duas safras, demonstrando ser o genótipo mais suscetível às podridões (Tabela 2). Em 2003, os híbridos Traktor e P32R21 não diferiram significativamente quanto a incidência de PC em todos os sistema de manejo. $\mathrm{Na}$ safra 2004, o Traktor apresentou incidência de PC significativamente menor do que as genótipos Planalto e P32R21 nos quatro sistemas de manejo (Tabela 2). Os valores numéricos obtidos nos dois anos demonstraram que o híbrido Traktor foi mais tolerante às PC.

Na safra 2004, as incidências de PC foram numericamente maiores do que em 2003 nos três 
Tabela 2 - Efeito de sistemas de manejo na incidência de podridões do colmo em diferentes genótipos de milho durante dois anos agrícolas. Lages, SC.

\begin{tabular}{|c|c|c|c|c|c|}
\hline \multirow{2}{*}{$\begin{array}{l}\text { Genótipo } \\
\text { Safra 2002/03 }\end{array}$} & \multicolumn{5}{|c|}{ Sistema de manejo / Incidência de podridões do colmo (\%) } \\
\hline & $\mathrm{S} 1^{1}$ & S2 & S3 & S4 & Média \\
\hline Planalto & $29,86 \mathrm{a} \quad \mathrm{A}^{2}$ & 18,42 a $B$ & 27,45 a $\mathrm{AB}$ & 25,69 a $A B$ & 25,35 \\
\hline Traktor & $1,14 \mathrm{~b} \mathrm{~A}$ & $1,24 \mathrm{~b} \mathrm{~A}$ & $4,80 \mathrm{~b} \mathrm{~A}$ & $3,71 \mathrm{~b}$ A & 2,72 \\
\hline P32R21 & $3,00 \mathrm{~b} \mathrm{~A}$ & $3,75 \mathrm{~b} \mathrm{~A}$ & $10,22 \mathrm{~b} \quad \mathrm{~B}$ & $5,01 \mathrm{~b} A$ & 5,49 \\
\hline Média & 11,33 & 7,80 & 14,16 & 11,47 & \\
\hline \multicolumn{6}{|l|}{ C.V. $(\%)=42,502$} \\
\hline \multicolumn{6}{|l|}{ Safra 2003/04 } \\
\hline Planalto & 49,30 a $\mathrm{A}$ & 38,42 a $\mathrm{A}$ & 39,98 a A & 23,90 a $B$ & 37,90 \\
\hline Traktor & 8,83 с A & $7,28 \mathrm{c} \mathrm{A}$ & 9,18 с A & $9,05 \mathrm{~b} A$ & 8,58 \\
\hline P32R21 & 29,18 b A & 22,40 b A & $22,30 \mathrm{~b}$ A & $18,54 \mathrm{ab} A$ & 23,10 \\
\hline Média & 29,10 & 22,70 & 23,82 & 17,16 & \\
\hline C.V. $(\%)=30,482$ & & & & & \\
\hline
\end{tabular}

${ }^{1}$ S1: baixo manejo; S2: médio manejo; S3: alto manejo; S4: produtividade potencial

${ }^{2}$ Médias seguidas de mesma letra, minúscula na coluna ou maiúscula na linha, não diferem significativamente pelo teste de Tukey, em nível de significância de $5 \%$.

genótipos (Tabela 2). Esse fato pode ser atribuído ao acúmulo de restos culturais infectados do milho, devido à monocultura, e conseqüente o aumento da densidade de inóculo dos patógenos necrotróficos (ZAMBOLIM et al., 2000; CASA et al., 2003).

A principal doença detectada com base na sintomatologia e no isolamento dos tecidos dos colmos foi a antracnose, causada pelo fungo $C$. graminicola, principalmente na variedade Planalto e no híbrido P32R21. Outros fungos identificados e isolados com maior freqüência foram: $\boldsymbol{F}$. verticillioides, $\boldsymbol{F}$. graminearum, S. maydis e $S$. macrospora. Os fungos Aspergillus spp., Cephalosporium sp., Nigrospora sp., Penicillium spp., Rhizopus sp. e Trichoderma sp. também foram detectados, porém em baixa freqüência. A predominância de $\boldsymbol{C}$. graminicola provavelmente ocorreu porque o milho foi cultivado sobre aveia preta, que é relatada como hospedeira do patógeno, o qual pode sobreviver saprofiticamente em seus restos culturais (HARDER \& HABER, 1992). O fungo $\boldsymbol{F}$. gramineraum também sobrevive em aveia (REIS \& CASA, 1997). No entanto, sua ocorrência foi menor do que a de $\boldsymbol{C}$. graminicola. Possivelmente os genótipos utilizadas apresentaram maior tolerância a $\boldsymbol{F}$. graminearum. No caso de $\boldsymbol{F}$. verticillioides, $\boldsymbol{S}$. maydis e $\boldsymbol{S}$. macrospora, a sobrevivência desses em restos culturais de aveia e no solo não é relatada. Portanto, os restos culturais do milho da safra anterior e as sementes são consideradas como fonte de inóculo primário.

De acordo com as características de cada sistema de manejo (Tabela 1), verificou-se que a alta população de plantas utilizada no S4 não apresentou as maiores incidências de PC (Tabela 2), como descrito por DENTI \& REIS (2001) e BOGO et al. (2003). Em 2003/04, as maiores incidências de PC no S1 nos genótipos Planalto e P32R21 (Tabela 2) podem estar relacionadas com a menor disponibilidade de nutrientes (HORN et al., 2003) e devido à alta infestação de plantas daninhas, principalmente papuã (Brachiaria plantaginea L.). A presença do papuã aumenta a competição nutricional e propicia sombreamento e umidade na região da base do colmo do milho. Além disso, o papuã é relatado como hospedeiro de G. zeae (REIS, 1988).

As produtividades médias de grãos na safra 2002/03 para S1, S2, S3 e S4 foram respectivamente de $4.114,5.078,9.416$ e $11.121 \mathrm{~kg} \mathrm{ha}^{-1}$, enquanto que na safra 2003/04 foram de 2.324, 3.771, $7.514 \mathrm{e}$ $10.947 \mathrm{~kg} \mathrm{ha}^{-1}$ (Tabela 3). Em 2002/03 não houve diferença no produtividade de grãos das genótipos em $\mathrm{S} 1$. Os híbridos foram significativamente mais produtivos do que a variedade de polinização aberta em S2, sendo que o híbrido simples apresentou maior produtividade de grão do que os demais genótipos em S3 e S4. No segundo ano agrícola, o híbrido simples apresentou maior produtividade do que os demais genótipos em todos os sistemas de manejo, embora não diferido estatisticamente do híbrido duplo em S1 e S2 (Tabela 3). Não houve uma associação direta entre incidência de $\mathrm{PC}$ e o produtividade de grãos, pois os menores valores de PC foram registrados para o híbrido Traktor (Tabela 2), enquanto que as maiores produtividades foram obtidas com o P32R21 (Tabela 
Tabela 3 - Efeito de sistemas de manejo na produtividade de grãos em diferentes genótipos de milho, durante dois anos agrícolas. Lages, SC.

\begin{tabular}{|c|c|c|c|c|c|}
\hline \multirow{2}{*}{$\begin{array}{c}\text { Genótipo } \\
\text { Safra 2002/03 }\end{array}$} & \multicolumn{5}{|c|}{ Sistema de manejo / Produtividade de grãos $\left(\mathrm{kg} \mathrm{ha}^{-1}\right)$} \\
\hline & $\mathrm{S} 1^{1}$ & S2 & S3 & S4 & Média \\
\hline Planalto & 4.090 a $C^{2}$ & 4.307 a $\mathrm{B}$ & $8.693 \mathrm{a} \mathrm{A}$ & $9.742 \mathrm{a} \mathrm{A}$ & 6.707 \\
\hline Traktor & 3.986 a C & $5.436 \mathrm{~b} \mathrm{~B}$ & $9.153 \mathrm{a} A$ & 10.131 a A & 7.176 \\
\hline $\mathrm{P} 32 \mathrm{R} 21$ & 4.265 a D & $5.492 \mathrm{~b} \mathrm{C}$ & $10.403 \mathrm{~b} \mathrm{~B}$ & $13.489 \mathrm{~b} \mathrm{~A}$ & 8.412 \\
\hline Média & 4.114 & 5.078 & 9.416 & 11.121 & \\
\hline \multicolumn{6}{|l|}{ C.V. $(\%)=8,75$} \\
\hline \multicolumn{6}{|l|}{ Safra 2003/04 } \\
\hline Planalto & $1.787 \mathrm{~b} \mathrm{D}$ & $2.861 \mathrm{~b} \quad \mathrm{C}$ & 6.239 с B & 8.774 с A & 4.915 \\
\hline Traktor & 2.344 ab D & $3.914 \mathrm{ab} \mathrm{C}$ & 7.229 b B & $10.217 \mathrm{~b} \mathrm{~A}$ & 5.926 \\
\hline $\mathrm{P} 32 \mathrm{R} 21$ & $2.841 \mathrm{a} \quad \mathrm{D}$ & $4.538 \mathrm{a} \quad \mathrm{C}$ & $9.074 \mathrm{a} \quad \mathrm{B}$ & $13.849 \mathrm{a} \quad \mathrm{A}$ & 7.575 \\
\hline Média & 2.324 & 3.771 & 7.514 & 10.947 & \\
\hline C.V. $(\%)=8,65$ & & & & & \\
\hline
\end{tabular}

${ }^{1}$ S1: baixo manejo; S2: médio manejo; S3: alto manejo; S4: produtividade potencial

${ }^{2}$ Médias seguidas de mesma letra, minúscula na coluna ou maiúscula na linha, não diferem significativamente pelo teste de Tukey, em nível de significância de $5 \%$.

3), na média dos quatro sistemas de manejo. Por outro lado, observou-se forte associação entre incidência de PC e a porcentagem de plantas acamadas e quebradas na colheita, as quais foram mais altas na variedade de polinização aberta Planalto (dados não apresentados).

Na safra 2002/03, a incidência média de grãos ardidos (GA) variou de $2,30 \%$ no S3, até $4,45 \%$ no S2. $\mathrm{Na}$ safra $2003 / 04$, a variação foi de $0,82 \%$ no $\mathrm{S} 4$, até $1,62 \%$ no S1 (Tabela 4). De modo geral, os patógenos envolvidos com as podridões do colmo são os mesmos relacionados com as podridões de espiga e grãos ardidos (REIS \& CASA, 2001). No entanto, não houve associação entre a incidência de PC e GA neste trabalho, principalmente em 2002/03, pois os menores valores de numéricos de PC foram obtidos em S2 (Tabela 2), justamente o sistema que apresentou maior incidência de grãos ardidos (Tabela 4). Uma das hipóteses para não ter havido esta associação é porque o fungo $\boldsymbol{C}$. graminicola predominou nos colmos infectados e não foi detectado nos grãos ardidos. O fungo $\boldsymbol{F}$. verticillioides predominou nos grãos ardidos nas duas safras, sendo que, em 2003, as incidências médias foram de 34,0, 20,5 e 16,5\%, respectivamente, para BRS Planalto, Traktor P P32R21.Em 2004, as incidências foram de 19,0, 16,0 e 18,25\%. A infecção dos grãos por $\boldsymbol{F}$. verticillioides pode ocorrer sistemicamente pelo micélio via planta mãe ou com inóculo depositado sobre a bainha foliar e também via estigma (MUNKVOLD et al., 1997). A baixa incidência de $\boldsymbol{F}$. verticillioides nos colmos é um indicativo de que sua predominância nos GA não deve ter ocorrido pela infecção sistêmica via planta mãe. A maior incidência de GA ocorre com o aumento na densidade de semeadura (TRENTO et al., 2002; BOGO et al., 2003). Essa tendência não foi verificada no presente trabalho, pois os sistemas $\mathrm{S} 3 \mathrm{e} \mathrm{S} 4$ tiveram maior densidade de semeadura, quando comparados aos sistemas S1 e S2, sem terem apresentado maior porcentagem de GA, principalmente na safra de 2003/ 04 (Tabela 4). O híbrido Traktor apresentou menor incidência média de GA, com valores absolutos de 2,25 $\%$ e $0,66 \%$, respectivamente, para as safras 2003 e 2004 (Tabela 4). Por outro lado, o híbrido P32R21 apresentou as maiores incidências médias de GA, com valores de $4,33 \%$ e $1,63 \%$, respectivamente, para 2003 e 2004 (Tabela 4). Contudo, as diferenças entre genótipos dentro de cada sistema de manejo nem sempre foram estatisticamente significativas, em função dos altos coeficientes de variação.

Os valores percentuais de GA nas duas safras foram baixos, nos três genótipos e nos quatro sistemas de cultivo, não atingindo o índice de $6 \%$ considerado para desconto no momento da comercialização dos grãos na indústria. A baixa percentagem de GA nas duas safras pode ter ocorrido em função da baixa precipitação pluvial registrada no mês de março, período que coincidiu com o final do enchimento de grãos e colheita.

\section{CONCLUSÕES}

O uso de bases genéticas contrastantes em milho influencia na incidência de podridões do colmo, 
Tabela 4 - Efeito de sistemas de manejo na incidência de grãos ardidos em diferentes genótipos de milho, durante dois anos agrícolas. Lages, SC.

\begin{tabular}{|c|c|c|c|c|c|}
\hline \multirow{2}{*}{$\begin{array}{l}\text { Genótipo } \\
\text { Safra 2002/03 }\end{array}$} & \multicolumn{5}{|c|}{ Sistema de manejo / Incidência de grãos ardidos (\%) } \\
\hline & $\mathrm{S} 1^{1}$ & $\mathrm{~S} 2$ & $\mathrm{~S} 3$ & $\mathrm{~S} 4$ & Média \\
\hline Planalto & 3,46 a $\mathrm{AB}^{2}$ & $6,21 \mathrm{a} \quad \mathrm{A}$ & 2,20 a $B$ & $3,51 \mathrm{a} \quad \mathrm{AB}$ & 3,84 \\
\hline Traktor & 2,44 a $\mathrm{A}$ & 3,35 b A & 1,31 a $\mathrm{A}$ & $1,90 \mathrm{~b} \mathrm{~A}$ & 2,25 \\
\hline P32R21 & 4,23 a $\mathrm{A}$ & $3,78 \mathrm{ab} A$ & 3,39 a $\mathrm{A}$ & 5,91 a $A$ & 4,33 \\
\hline Média & 3,38 & 4,45 & 2,30 & 3,77 & \\
\hline \multicolumn{6}{|l|}{ C.V. $(\%)=43,56$} \\
\hline \multicolumn{6}{|l|}{ Safra 2003/04 } \\
\hline Planalto & 1,61 a $\mathrm{AB}$ & 2,10 a $\mathrm{A}$ & 1,67 a $A B$ & $0,77 \mathrm{a} \quad \mathrm{B}$ & 1,54 \\
\hline Traktor & 1,08 a $\mathrm{A}$ & 0,77 b A & 0,50 a $A$ & 0,32 a $A$ & 0,66 \\
\hline P32R21 & 2,19 a $\mathrm{A}$ & $1,44 \mathrm{ab} A$ & 1,51 a $A$ & 1,38 a A & 1,63 \\
\hline Média & 1,62 & 1,44 & 1,22 & 0,82 & \\
\hline C.V. $(\%)=53,035$ & & & & & \\
\hline
\end{tabular}

${ }^{1} \mathrm{~S} 1$ : baixo manejo; S2: médio manejo; S3: alto manejo; S4: produtividade potencial

${ }^{2}$ Médias seguidas de mesma letra, minúscula na coluna ou maiúscula na linha, não diferem significativamente pelo teste de Tukey, em nível de significância de $5 \%$.

grãos ardidos e produtividade de grãos. A variedade de polinização aberta apresenta maior suscetibilidade às podridões do colmo do que os híbridos duplo e simples, independentemente do sistema de manejo adotado para o cultivo. A antracnose é a principal doença associada às podridões do colmo, principalmente quando o milho é cultivado no sistema plantio direto em monocultura, mesmo em áreas com diferentes níveis tecnológicos. A maximização da produtividade de grãos é influenciada pelo nível tecnológico, sendo obtida no sistema de manejo que visa maior potencial produtivo.

\section{REFERÊNCIAS}

BOGO, A. et al. Efeito de densidades de semeadura em diferentes híbridos de milho na incidência de podridões do colmo e de grãos ardidos. In: REUNIÃO TÉCNICA CATARINENSE DE MILHO E FEIJÃO, 4., 2003, Lages, SC. Resumos... Lages, 2003. p.153-156.

BRASIL. Portaria no 11 de 12 de abril de 1996. Estabelece critércios complementares para classificação do milho. Diário Oficial da União, Brasília, n.72, 1996.

CASA, R.T. et al. Fungos associados à semente de milho produzida nas Regiões Sul e Sudeste do Brasil. Fitopatologia Brasileira, Brasília, v.23, n.3, p.370-373, 1998.

CASA, R.T. et al. Decomposição dos restos culturais do milho e sobrevivência saprofítica de Stenocarpella macrospora e Stenocarpella maydis. Fitopatologia Brasileira, Brasília, v.28, n.4, p.355-361, 2003.

DENTI, E.A.; REIS, E.M. Efeito da rotação de culturas, da monocultura e da densidade de plantas na incidência das podridões da base do colmo e no produtividade de grãos do milho. Fitopatologia Brasileira, Fortaleza, v.26, n.3, p.635-639, 2001.

HARDER, D.E.; HABER, S. Oat diseases and pathology techniques. In: MARSHALL, H.G.; SORRELLS, M.E. (Eds). Oat Science and Technology, Madison: American Society of Agronomy, 1992. p.354-357.

HORN, D. et al. Cinética da absorção de potássio em genótipos de milho contrastantes quanto a variabilidade genética. In: REUNIÃO TÉCNICA CATARINENSE DE MILHO E FEIJÃO, 4., 2003, Lages, SC. Resumos... Lages, 2003. p.201-205.

INDICAÇÕES TÉCNICAS. Indicações técnicas para a cultura do milho no Rio Grande do Sul. Porto Alegre: FEPAGRO; EMATER/RS; FECOAGRO/RS, 2001. 196p.

MUNKVOLD, G.P. et al. Importance of different pathways for maize kernel infection by Fusarium moniliforme. Phytopathology, St. Paul, v.87, n.2, p.209-217, 1997.

PEREIRA, O.A.P. Doenças do milho. In: KIMATI, H. et al. Manual de fitopatologia: doenças das plantas cultivadas. 3.ed. São Paulo: Agronômica Ceres, 1997. V.2, p.538-555.

PINTO, N.F.J.A. Patologia de sementes de milho. Sete Lagoas: EMBRAPA-CNPMS, 1998. 44p. (EMBRAPACNPMS, Circular Técnica, 29).

REIS, E.M. Doenças do trigo III: giberela. 2.ed. Revista e ampliada. São Paulo: [s.n.], 1988. 13p.

REIS, E.M.; CASA, R.T. Cereais de inverno. In: VALE, F.X.R.; ZAMBOLIM, L. Controle de doenças de plantas: grandes culturas. Viçosa: Universidade Federal de Viçosa, 1997. V.1, cap.5, p.231-289.

REIS, E.M.; CASA, R.T. Controle de doenças fúngicas na cultura do milho em plantio direto. In: BORGES, G.; BORGES, L.D. Seminário sobre tecnologia de produção e comercialização 
do milho, 2000, Passo Fundo, RS. Resumo de Palestras... Passo Fundo: Aldeia Norte, p.62-71.

REIS, E.M.; CASA, R.T. Milho: manejo integrado de doenças. In: FANCELLI, A.L.; DOURADO NETO, D. Milho: tecnologia e produtividade. Piracicaba: ESALQ/LPV, 2001. p.223-237.

REIS, E.M. et al. Manual de diagnose e controle de doenças do milho. Passo Fundo: Aldeia Norte, 2004. 141p.
TRENTO, S.M. et al. Efeito da rotação de culturas, da monocultura e da densidade de plantas na incidência de grãos ardidos em milho. Fitopatologia Brasileira, Fortaleza, v. 27, n.4, p.609-613,2002.

ZAMBOLIM, L. et al. Sistema plantio direto e doenças em plantas. Fitopatologia Brasileira, Fortaleza, v.25, n.4, p.585-595, 2000 